\title{
EDUCAÇÃo INDÍGENA: DESAFIOS PARA AS ESCOLAS NÃO INDÍGENAS EM BARRA DO GARÇAS-MT
}

\author{
INDIGENOUS EDUCATION: CHALLENGES FOR NON INDIGENOUS SCHOOLS \\ IN BARRA DO GARÇAS-MT
}

DOI: http://dx.doi.org/10.23926/RPD.2526-2149.2019.v4.n1.p317-333.id394

\section{Rosangela Santos da Silva \\ Especialista em Libras e \\ Educação Inclusiva \\ (IFMT/UAB) \\ Professora na Secretaria \\ Municipal de Araguaiana \\ (SMA/MT) \\ rssarq@hotmail.com}

\section{Marilene Marzari \\ Doutora em Educação pela \\ Pontifícia Universidade \\ Católica de Goiás (PUC-GO) \\ Professora no Campus \\ Universitário do Araguaia \\ (CUA/UFMT) \\ marilenemarzari@gmail.com}

Resumo: Os avanços das políticas públicas indigenistas, desencadeadas a partir das lutas e movimentos indígenas, mais especificamente das relacionadas com a educação escolar, motivaram o desenvolvimento de uma pesquisa que teve como objetivo entender o processo de inclusão escolar dos alunos indígenas nas escolas públicas não indígenas, na cidade de Barra do Garças/MT, em decorrência do qual alinharam-se os objetivos específicos: compreender as políticas educacionais voltadas à educação dos indígenas nas escolas públicas não indígenas e saber o que dizem os professores a respeito da presença de indígenas em tais escolas. Para subsidiar teoricamente a produção utilizou-se de autores, como Cohn (2001), Grupioni (2005), Pagliaro (2005) que tratam dos povos indígenas no Brasil e de Both (2009), entre outros, que discutem a educação escolar indígena. A metodologia qualitativa e os procedimentos de entrevista, de observação e de análise documental permitiram o levantamento dos dados a respeito do processo educacional indígena, no Brasil, no estado de Mato Grosso e, consequentemente, em Barra do Garças. Os resultados indicam que a educação escolar indígena nas escolas não indígenas ainda precisa avançar, principalmente no que diz respeito à língua e à superação do preconceito e da discriminação que os indígenas enfrentam no contexto escolar.

Palavras-chave: Políticas Públicas; Educação Escolar Indígena; Inclusão Escolar.

\begin{abstract}
The advances of Indian public policies, triggered by indigenous struggles and movements, more specifically those related to school education, motivated the development of a research that aimed to understand the process of school inclusion of indigenous students in non indigenous public schools, in the city of Barra do Garças / MT, as a result of which the specific objectives were aligned: to understand educational policies aimed at the education of indigenous people in non-indigenous public schools and to know what teachers say about the presence of indigenous people in such schools. In order to theoretically subsidize production, authors such as Cohn (2001), Grupioni (2005), Pagliaro (2005) dealing with indigenous peoples in Brazil and Both (2009), among others, discuss indigenous school education. The qualitative methodology and the procedures for interview, observation and documentary analysis allowed the data to be collected regarding the indigenous educational process in Brazil, in the state of Mato Grosso and, consequently, in Barra do Garças. The results indicate that indigenous school education in non-indigenous schools still needs to be advanced, especially with regard to language and the overcoming of prejudice and discrimination faced by indigenous people in the school context
\end{abstract}

Keywords: Public Policy; Indigenous school education; School inclusion. 


\section{INTRODUÇÃO}

O interesse em desenvolver uma pesquisa a respeito do tema "inclusão escolar dos alunos indígenas" surgiu, durante a realização do estágio supervisionado, referente ao curso de Licenciatura em Geografia, em uma escola estadual de Barra do Garças-MT. Em sala, estavam presentes alunos indígenas que nos instigaram a saber mais a respeito de seu processo de aprendizagem. Para isso, tentamos nos aproximar da classe, para ensinar os conteúdos de Geografia, mas, depois de dois meses, concluímos o estágio com muitas indagações e dúvidas a respeito da aprendizagem dos conteúdos de Geografia, principalmente por parte dos alunos indígenas.

Outro motivo que desencadeou a decisão de pesquisar o tema foi o diálogo com os professores das escolas, que relataram uma série de dificuldades, envolvendo o processo de ensino-aprendizagem dos alunos indígenas. Essas questões nos levaram a vários questionamentos em relação à inclusão desses alunos em escolas não indígenas: Como tem sido a inclusão dos alunos indígenas no ambiente escolar? Por que os indígenas dificilmente se relacionam com colegas não indígenas? Como os professores ensinam os alunos indígenas? Como tem sido a aprendizagem dos alunos indígenas nas escolas urbanas? Esses questionamentos contribuíram para a elaboração do problema de pesquisa: Como tem sido a educação escolar dos alunos indígenas nas escolas públicas não indígenas da cidade de Barra do Garças-MT?

O objetivo geral consistiu em entender o processo de educação dos alunos indígenas nas escolas públicas não indígenas da cidade de Barra do Garças/MT. Os objetivos específicos visaram: conhecer as políticas educacionais voltadas à educação dos indígenas nas escolas não indígenas e saber o que dizem os professores a respeito da presença de alunos indígenas em tais escolas.

O estudo pautou-se na metodologia qualitativa que, segundo Lakatos; Marconi (2003) preocupa-se com o aprofundamento da compreensão do tema, a partir de um grupo social ou de uma organização. Essa perspectiva de pesquisa permite a utilização de diferentes procedimentos que, neste estudo, foram a entrevista semiestruturada, a observação e a análise de documentos.

Em relação à educação escolar, a Seção I, do Cap. III, do Art. 205 da Constituição Federal diz que a educação é "[...] direito de todos e dever do Estado [...]”. (MORAES, 2015, p. 126). Nessa mesma perspectiva, a Lei de Diretrizes e Bases da Educação Nacional - LDB n. 
9.394/96 garante o acesso da população à educação. Assim, todos têm direito a uma educação pública, inclusiva e de qualidade social, pois é um direito de todo cidadão.

Nesse sentido, é necessário um processo de inclusão, principalmente dos que estão em desvantagem dentre a maioria, para ter, na escola, um ensino que visa:

\begin{abstract}
$\left.1^{\circ}\right)$ Proporcionar aos índios, suas comunidades e povos a recuperação de suas memórias históricas, a reafirmação de suas identidades étnicas; a valorização de suas línguas e ciências; $2^{\circ}$ ) garantir aos índios, suas comunidades e povos o acesso às informações e conhecimentos técnicos e científicos da sociedade nacional e demais sociedades indígenas e não-indígenas (BRASIL, 1996, p. 25).
\end{abstract}

Dessa maneira, a educação escolar tem papel importante, no sentido de valorizar a história dos diferentes povos e “[...] abrir caminhos para o acesso a outros conhecimentos universais, necessários e desejáveis, a fim de contribuírem com a capacidade de responder às novas demandas geradas a partir do contato com a sociedade global" (SANTOS Apud SIMAS, 2010, p. 07). Por isso, a importância das instituições de ensino estarem abertas às mudanças, principalmente no que diz respeito às diferenças e ao desenvolvimento de ações didáticopedagógicas que possibilitem a inclusão no processo de ensino-aprendizagem.

A partir dessa perspectiva, o estudo procurou entender o processo de inclusão dos alunos indígenas que, por diferentes motivações, migram de suas aldeias para frequentar escolas públicas não indígenas da cidade de Barra do Garças/MT.

Para o referido estudo, optamos por organizar o texto com um breve histórico dos povos indígenas e da educação brasileira pensada para eles e, na sequência, a história dos Xavante, no Estado de Mato Grosso, e das políticas estaduais de educação.

\title{
2 Povos INdíGENAS No BRASIL: Diversidade CULTURAL
}

A maioria da população brasileira desconhece a quantidade de povos indígenas existentes no Brasil. De acordo com o Instituto Socioambiental -ISA (2017), existem 252 povos falantes de mais de 150 línguas. A maioria desses povos, segundo o Instituto Brasileiro de Geografia e Estatística - IBGE- (2010), localiza-se na Região Norte, com 305.873 habitantes e a menor proporção na Região Sul, com 7.495 habitantes.

O Brasil é formado por 5.565 municípios, sendo que, destes, 12 concentram $50 \%$ da população declarada indígena e localizam-se, em sua maioria, nas regiões Norte e Nordeste do Brasil. No Estado de Mato Grosso, o município de Campinápolis, localizado na região nordeste mato-grossense, faz parte dessa estatística, ao computar uma população de 7.621 Xavante de um total de 13.000 que habitam o estado. 
Para o Instituto Socioambiental (2017), a população indígena, no século XVI, ficava entre 2 e 4 milhões de habitantes, pertencentes a mais de 1.000 povos diferentes. Somente na primeira metade do século XX, segundo Ribeiro (1957), desapareceram mais de 80 povos indígenas, diminuindo de 1.000.000 habitantes para 200.000. Essa redução da população indígena, de acordo com o autor, teria ocorrido em função do extermínio por epidemias, conflitos armados, desorganização social e cultural, dentre outros.

Nas últimas décadas, segundo censo do IBGE (2010) e relatos de Azevedo (2017), as populações indígenas tiveram crescimento no número de nascimentos e diminuição na mortalidade infantil. Isso mostra o resultado positivo de políticas públicas, como as ações de saúde pública desencadeadas, principalmente, pelos programas de vacinação.

Essas políticas têm contribuído, de certa maneira, para manter a riqueza da diversidade cultural dos povos indígenas, dentre as quais destacam-se as tradições, as línguas, os costumes, os mitos e as crenças derivadas dos antepassados que se constituem na "[...] importância da cultura dos povos indígenas na formação do povo brasileiro, remete a conhecer a história e cultura de nossos antepassados para saber quem somos e de quem somos descendentes" (SOUZA, 2016, p. 06).

\subsection{EDUCAÇÃO PARA OS POVOS INDÍGENAS NO BRASIL}

Os estudos que tratam da educação escolar indígena consideram que as primeiras experiências de alfabetização e catequização dos povos indígenas ocorreram com os missionários Jesuítas que migraram da Europa para expandir a fé cristã, durante o período de colonização do Brasil pelos portugueses. Esse processo de catequização e alfabetização ignorava as particularidades culturais, ao imprimir uma educação que obrigava os indígenas, segundo Teixeira (1995), a falar o português, a acreditar em Deus e a abandonar hábitos culturais cultivados há milênios. Assim, as escolas "civilizadas" que os Jesuítas impuseram aos indígenas foram exemplos de violência cultural.

Somente nos primeiros anos do período republicano brasileiro, segundo Franco (2008), foram criadas as primeiras ações do Estado em relação às comunidades indígenas, tanto na institucionalização de um órgão específico voltado para a questão indígena, como na fixação de uma base sólida de ação indigenista. Isso se deu com a criação do Serviço de Proteção aos Índios - SPI -, em 1910, que tinha como finalidade assistir as populações nativas e integrá-las à sociedade nacional, na condição de pequenos lavradores, juntamente com a população sertaneja. Para isso, “[...] a educação escolar indígena promovida pelo SPI, enquanto parte de 
um projeto de exercício tutelar, serviu para atrair, transformar e educar, propósito de plena integração das populações indígenas na vida 'civilizada"” (FRANCO, 2008, p. 08).

Durante as décadas posteriores, as políticas em relação à educação dos povos indígenas mantiveram-se com poucas alterações. Somente a partir da década de oitenta do século XX, com o processo de redemocratização do país, os movimentos sociais, dentre eles os indígenas, organizaram-se e contaram com o apoio de antropólogos, religiosos, Organizações Não Governamentais - ONG's -, entre outros, que lutaram por políticas públicas, tanto voltadas para a demarcação de terras e assistência à saúde como para o desenvolvimento de projetos educacionais voltados às suas necessidades.

Nesse sentido, a partir dos anos 1980, “[...] muitos estudos sobre educação indígena começaram a ser realizado no país, trazendo novas contribuições para uma visão mais crítica da educação indígena, cujas práticas começaram a ser objetos de estudo e de pesquisa” (BOTH, 2009, p.35)

Esses estudos contribuíram para assegurar, na Constituição Federal de 1988, o reconhecimento de direitos aos povos indígenas, dentre eles, o direito à terra, o respeito à diferença cultural e linguística, as políticas públicas de assistência, o direito à educação, como expresso no Parágrafo $2^{\circ}$ do Art. 210 que diz: "O ensino fundamental regular será ministrado em língua portuguesa, assegurada às comunidades indígenas também a utilização de suas línguas maternas e processos próprios de aprendizagem". (MORAES, 2015, p. 222). Além disso, o Parágrafo $1^{\circ}$ do Art. 215 pontua que: “[...] o Estado protegerá as manifestações das culturas populares, indígenas e afro-brasileiras, e das de outros grupos participantes do processo civilizatório nacional" (MORAES, 2015, p. 226).

Assim, a partir da Constituição Federal de 1988 os indígenas têm o direito de escolas que reconheçam seus saberes e a cultura não indígena. Nessa perspectiva, cria-se a necessidade de ensino diferenciado e programas de formação de professores para atender essas especificidades.

Nesse contexto, Silva \& Grupioni (1995), pontuam que o Decreto nº 26 de 1991 transferiu a responsabilidade da oferta de ensino da Fundação Nacional do Índio - FUNAI para o Ministério da Educação - MEC - em parceria com as Secretarias Estaduais e Municipais de Educação. Para os autores essa transferência permitiu uma maior integração das políticas educacionais e de 'pressão' sobre os estados, para assumirem a educação como política pública.

Isso desencadeou toda uma discussão, principalmente em relação à alfabetização das crianças na língua materna, visto que é a língua falada no cotidiano. Em relação a isso, o 
Instituto Socioambiental (2017) defende que a escola tem a responsabilidade de incluir a língua indígena no currículo escolar e de atribuir o status de língua plena, como um direito dos povos indígenas. Além disso, a educação indígena precisa considerar

[...] dois aspectos que caracterizam a educação indígena: o reforço à identidade e a importância dos sonhos no processo educativo. Ou seja, conhecendo seu povo, a criança sabe de onde vem, quem ela é e qual sua expectativa de futuro. Essas informações ajudam-na a individualizar-se e definir-se a partir da história do grupo e, ao mesmo tempo, ajudam-na a entender-se como parte de um povo etnicamente diferente. Essa visão mostra como o passado é importante para a cultura nativa, é a herança da pessoa, a certeza de sua identidade (MUNDURUKU Apud SIMAS, 2010, p. 06).

Esses direitos e garantias estão resguardados na Constituição Federal de 1988, na Lei de Diretrizes e Bases nº. 9394/96, na Resolução CNE/CEB nº. 3 de 1999, nos Planos Nacional de Educação - PNE - (2001-2011) e (2014-2024) e no Estatuto do Índio. Além desses documentos, o Referencial Curricular Nacional para as Escolas Indígenas - RCNEI - (1998) traz diferentes práticas que podem contribuir com a educação escolar indígena. Dessa maneira, podemos dizer que tais legislações trazem conquistas e avanços importantes para esses povos, mas que ainda carecem de ações concretas para efetivar as necessidades educacionais e profissionais desejadas.

\section{Os Xavante no estado de Mato Grosso}

Os Xavante têm uma história marcada por movimentos humanos e territoriais, pois foram pressionados a deixar sua terra, no norte de Goiás, por imposição de colonizadores, no século XIX, e migrarem para Mato Grosso, localizando-se entre os rios Araguaia e das Mortes.

Conforme o Instituto Socioambiental/Povos Indígenas no Brasil (2017), no ano de 2007, os Xavante somavam cerca de 13.000 habitantes, residentes em diversas Terras Indígenas, localizadas em espaços que compreendem a Serra do Roncador, passando pelos Rios das Mortes, Kuluene, Couto de Magalhães, Batovi e Rio Garças. Além dessas terras, existem as que são geograficamente descontínuas, formadas pelo Chão Preto e Ubawawe, São Marcos, Pimentel Barbosa, Areões e Sangradouro.

De acordo com Cohn (2001), a sociedade indígena reúne costumes culturais e modos de vida originários de seus ancestrais, passados de geração para geração, e caracterizam a rica diversidade cultural, pois cada povo possui cultura e modos de vida diferenciados.

Isso, de acordo com Silva \& Grupioni, denomina-se cultura, um “[...] conjunto de símbolos compartilhado pelos integrantes de determinado grupo social e que lhes permite atribuir sentido ao mundo em que vivem e às suas ações" (SILVA \& GRUPIONI, 1995, p. 434). 
Assim, o homem constitui o pensamento simbólico que o diferencia dos outros animais pela capacidade de criar e manter a cultura.

Outro aspecto da cultura indígena são os rituais e as festas que expressam os momentos importantes da vida do grupo. Esses rituais reforçam a identidade e fazem com que "[...] as culturas indígenas não se percam e que as sociedades indígenas atuam sempre na reconstituição de uma identidade diferenciada" (COHN, 2001, p. 37).

A respeito da organização social Xavante destaca-se o agrupamento em arranjos binários, ou seja, em classes matrimoniais, nas quais “[...] os sistemas de clãs e de linhagens são fundamentais na organização social Xavante que possuem um sistema de clãs patrilineares, são eles: Po'redza'õno e Öwawe, e, em algumas comunidades, pode-se ter o clã tob' ratato (PAGLIARO et. al., 2005, p. 63).

Outros aspectos culturais, segundo o Instituto Socioambiental (2017), são os cerimoniais, como a perfuração de orelhas, que consiste no " [...] auge da iniciação para a vida adulta Xavante [...] inscrição máxima da maturidade e da pertença à sociedade Xavante no corpo do rapaz" (LOPES DA SILVA Apud DELUCI, 2013, p. 109). Essa cerimônia tem como objetivo educar os jovens para a coragem e a responsabilidade da vida adulta.

\subsection{A EDUCAÇÃO ESCOLAR INDÍGENA NO ESTADO DE MATO GROSSO}

No Estado de Mato Grosso, a Educação Escolar Indígena ganha maior visibilidade, a partir da Lei n. 11.695, de 10 de março de 2008, que incluiu a obrigatoriedade da "História e Cultura Afro-Brasileira e Indígena" no currículo oficial da Educação Básica. A referida Lei pontua a necessidade de

[...] estudar, conhecer, compreender a temática indígena. Superar desinformações, equívocos e a ignorância que resultam em estereótipos e preconceitos sobre os povos indígenas. Reconhecendo, respeitando e apoiando os povos indígenas nas reivindicações, conquistas e garantias de seus direitos e em suas diversas expressões socioculturais (SILVA Apud SOUZA, 2016, p. 7).

Essa Lei soma-se a outros documentos, como o RCNEI de 1998, que visam atender as reivindicações dos professores por uma proposta curricular que favoreça a realidade dos povos indígenas; a Resolução n. 201 de 2004 que regulamenta o funcionamento das escolas indígenas no estado e o Plano Estadual de Educação (2008-2018) que diz: “A Educação indígena é fundamentada na concepção da inclusão, respeitando a diversidade humana, tendo como princípios a garantia do acesso e permanência de todos à Educação" (MATO GROSSO, 2014, p. 35). 
A partir de 2008 a Secretaria Estadual de Mato Grosso-SEDUC - iniciou as discussões para a elaboração das Orientações Curriculares para a Educação Básica - Ocs -, com o objetivo de "[...] ampliar e fortalecer a educação para aprendizagem de valores humanos, dentre os quais, a ética, o respeito, a cidadania, a solidariedade, a justiça e o protagonismo social, visando a vivência de uma cultura de direitos humanos" (MATO GROSSO, 2012, p. 21). Compõe as OCs um caderno específico para as diversidades educacionais. Em relação às questões indígenas foram realizadas discussões com tais povos, a respeito da "escola desejada" que envolvia os princípios básicos para a sua educação - respeito pelas formas tradicionais de organização social e cosmológica dos povos indígenas - e pelos modos próprios de produzirem e transmitirem seus conhecimentos. Além disso, ficaram definidas questões referentes à administração dos recursos financeiros e a organização e gestão escolar.

Nesse sentido, as OCs atendem o Inciso III, do Art. 10, do Capítulo I da Constituição Estadual de 1989, que diz:

[...] ninguém será prejudicado ou privilegiado em razão de nascimento, raça, cor, sexo, estado civil, natureza de seu trabalho, idade, religião, orientação sexual, convicções políticas ou filosóficas, deficiência física ou mental e qualquer particularidade ou condição (MATO GROSSO, 1989, p. 19).

Nessa mesma perspectiva, o Plano Estadual de Educação diz que “A Educação indígena é fundamentada na concepção da inclusão, respeitando a diversidade humana, tendo como princípios a garantia do acesso e permanência de todos à Educação". (MATO GROSSO, 2014, p. 35). Diante disso, é preciso que a população tenha consciência da necessidade de indignarse com qualquer tipo de preconceito ou discriminação, principalmente nos sistemas de ensino, para que todos tenham acesso e aprendam no ambiente escolar. Portanto, todas

[...] as escolas devem contemplar em seus Projetos Político-Pedagógicos práticas pedagógicas dialógicas, interativa e interdisciplinar de educação inclusiva, que identifique as habilidades e as necessidades de cada estudante [...] a criação de estratégias didático-pedagógicas que atendam o desenvolvimento e a aprendizagem dos alunos [...] (LIMA, 2016, p. 48).

As mudanças conquistadas, a partir da Constituição Federal de 1988, garantiram aos povos indígenas também o direito de migrarem em busca de ensino nas escolas urbanas, a fim de terem a "[...] possibilidade de estudar e ter uma profissão, de cursar o ensino superior e, consequentemente, defender sua nação indígena" (OLIVEIRA, 2014, p.244). A busca pela escolarização urbana tem crescido nos últimos anos, tanto que algumas famílias migram para a cidade de Barra do Garças, a fim de que os filhos frequentem escolas não indígenas, por um lado, para apropriar-se da língua portuguesa e, por outro, por acreditarem que essas escolas 
preparam melhor seus filhos para prosseguirem os estudos e/ou ingressarem no mercado de trabalho.

\section{Metodologia}

A pesquisa contou com as contribuições da abordagem qualitativa que, por meio do contato direto com a situação estudada, expressa a realidade, de forma descritiva. Assim, segundo Ludke e André (1986), esse tipo de pesquisa enfatiza mais o processo do que o produto e mantém o foco na perspectiva dos participantes. Para as autoras, esse tipo de pesquisa lida com significados, crenças, atitudes e valores, demonstrando as relações dos fenômenos, ou seja, ela aprofunda a compreensão de determinados grupos sociais ou organizações, sem preocuparse com representatividades numéricas. Além disso, possibilita diferentes procedimentos, dentre eles a observação, a entrevista semiestruturada e a análise de documentos que fazem parte deste estudo.

A observação permite um contato pessoal e estreito do pesquisador com o fenômeno estudado, evidenciando aspectos relacionados com o problema. Assim, a observação “[...] é sem dúvida o melhor teste de verificação da ocorrência de um determinado fenômeno" (LÜKE; ANDRÉ, 1986, p. 26). Ela contribuiu para entendermos a dinâmica do contexto escolar e da sala de aula, envolvendo, principalmente professores, alunos indígenas e não indígenas e o processo de ensino-aprendizagem. Para isso, as observações ocorreram no período de fevereiro a maio de 2016, em uma escola pública de Barra do Garças, durante a realização do estágio supervisionado e da regência efetuada por alunos do curso de licenciatura em Geografia.

Em relação à entrevista semiestruturada, Lüdke, André (1986) dizem que ela proporciona um ambiente mais informal entre o pesquisador e o pesquisado, além de facilitar o levantamento de dados qualitativos. A entrevista semiestruturada foi realizada com 05 professores da rede pública de ensino e versaram a respeito do tempo de experiência na docência; o ensino de temas envolvendo os povos indígenas; a abordagem do tema nos livros didáticos; a avaliação em relação à participação e o desempenho dos alunos indígenas na sala de aula; as práticas que poderiam ser melhoradas ou implantadas; a inclusão dos alunos indígenas na sala de aula e o relacionamento dos não indígenas com os indígenas, no contexto escolar.

Por fim, a análise de documentos se constitui num procedimento que busca reconhecer as informações, a partir das inquirições e dos interesses do pesquisador. Neste estudo, utilizamos documentos, como a Constituição Federal de 1988, a Lei de Diretrizes e Bases da 
Educação Nacional - LDB n. 9394/96 -, os Referenciais Curriculares Nacionais de Educação Indígena- RCNEI de 1998 -, as Orientações Curriculares da Secretaria Estadual de Educação de MT e das políticas de inclusão das populações historicamente marginalizadas, especialmente em relação à educação escolar indígena em escolas não indígenas.

A pesquisa contou com a participação de 05 professores $^{1}$. Destes, 02 atuam em sala de aula, sendo 01 professor licenciado em Letras (J.S.R.), com 15 anos de experiência na Educação Básica e 01 professor (M.L.A) com formação em Pedagogia e História e mais de 18 anos atuando como professor na Educação Básica; 01 professora (I.V.J) licenciada em História, com mais de 30 anos de carreira, sendo que a maior parte deles atuando nos anos iniciais do Ensino Fundamental da rede municipal de educação e, há 09 anos, responsável pelos Assuntos Indígenas de Barra do Garças-MT, junto à Secretaria Municipal de Educação; 01 professora (L.M.R.) licenciada em Pedagogia e História, com 25 anos atuando, ora em sala de aula, nos anos finais do Ensino Fundamental e Médio, ora na formação continuada, no Centro de Formação e Atualização dos Profissionais da Educação (CEFAPRO), onde, nos últimos 12 anos, atende a educação escolar indígena Xavante, Bororo, entre outras etnias, que fazem parte do Polo de Barra do Garças e 01 professor indígena (C.T.T), liderança do povo Xavante, Filósofo e licenciado em História. Há mais de 25 anos atua na educação e desenvolve projetos no departamento de educação indígena do município, em prol do povo Xavante. É importante registrar que todos esses profissionais possuem experiência superior a 15 anos, ora atuando em sala de aula, ora na administração pública educacional, ou com a formação continuada.

\section{Resultados}

Em relação à inserção da história e cultura indígena em sala de aula, conforme a Lei nº 11.645, de 10 março de 2008, os professores que atuam em sala afirmam que passaram a abordar o tema, com maior intensidade, a partir de sua criação. A professora D.D.O. fala da necessidade de discutir o tema, pelo menos durante o mês de abril, em função do Dia do Índio e do Descobrimento do Brasil e, no mês de agosto, nas comemorações do Folclore. Além disso, a professora acredita que todas as escolas trazem em seus projetos político-pedagógicos-PPP- as questões indígenas, mas, no geral, a ênfase recai sobre as datas comemorativas. Nesse sentido,

Quais são os efeitos de se falar sobre os povos indígenas inserindo-os num discurso comemorativo? Foi no ano de 1943 que Getúlio Vargas através do decreto 5.540 institui o 19 de Abril como Dia do Índio. E dessa forma, o termo 'índios' passa a compor os currículos escolares, enquadrado numa perspectiva comemorativa, o que dificulta uma abordagem mais profunda da temática, que considere os conflitos,

\footnotetext{
${ }^{1}$ Os professores entrevistados foram identificados pelas iniciais dos nomes.
} 
genocídios e as violências (afinal, sofrimento e tristezas não 'cabem' num momento de comemoração (BONIN, 2012, p. 02).

Essa prática tem sido ratificada pelos livros didáticos que tratam o tema de forma aligeirada e pontual. Ampliar as discussões em sala de aula implica a realização de pesquisas e leituras que possibilitem aos educadores perceberem

\begin{abstract}
[...] o contraste existente entre o material didático disponível sobre o assunto e as informações veiculadas na mídia sobre a atuação dos movimentos indígenas. Mesmo tratando estas populações de forma preconceituosa ou idealizada, os noticiários acabam revelando que os índios são nossos contemporâneos e fazem parte de nosso país. Dividem conosco o território, participam o quanto podem da elaboração das leis, elegem candidatos, sofrem ao nosso lado com os efeitos de uma economia desestabilizada ou da poluição ambiental. Desta forma, ensinar aos alunos sobre a situação política, econômica e social do nosso país, é também fornecer-lhes informações mais corretas e menos preconceituosas a respeito dos povos indígenas. Igualmente, trabalhar o tema indígena com os alunos é também fazê-los conhecer melhor a realidade do país e refletir sobre a nação que almejam para o futuro (GRUPIONI, 1995, p. 467).
\end{abstract}

Isso requer muito estudo e preparação por parte dos profissionais da educação para exercitar o respeito às diferenças e evitar preconceitos e discriminação "[...] seja ela de gênero, de cor, de religião, de constituição física ou, como neste caso, a diferença étnica e cultural" (GRUPIONI, 1995, p. 467).

Os professores que estão em sala, por um lado, sabem da complexidade em abordar o tema, no decorrer do período letivo, mas não veem dificuldade quando as ações são pontuais: "[...] no mês dedicado à cultura indígena não é difícil. Difícil é manter o tema no decorrer do ano" (M.L.A. ${ }^{2}$ ). A fala expressa duas questões importantes: uma refere-se ao conhecimento necessário para discutir questões complexas como as trazidas acima por Grupioni e a outra que dispensa um aprofundamento teórico, pois resume-se a enfeites, danças, comidas típicas, entre outras, que requerem apenas conhecimentos empíricos. O professor M.L.A. justifica isso, dizendo que os recursos didáticos deixam a desejar. Por isso, acabam convidando um professor indígena para dialogar com os alunos, para que eles conheçam melhor a cultura indígena e, em outros momentos, levam indígenas para dançar e entoar cantos culturais.

Nesse sentido, a professora I.V.J. relata que os recursos didáticos fornecidos pela Secretaria Municipal de Educação - SME - para as escolas das aldeias deixam de priorizar questões específicas da cultura indígena. Porém, alguns professores indígenas desenvolvem projetos relacionados às danças, aos artesanatos e às atividades esportivas. De certa forma, essas ações individuais e pontuais, de um ou outro professor, acabam contribuindo para desconstruir preconceitos e afirmar a identidade dos povos indígenas.

\footnotetext{
2 - Entrevista realizada em agosto de 2017.
} 
Desse modo, a professora L.M.R. ratifica que os livros didáticos deixam de contemplar as questões indígenas e cita o escritor Daniel Munduruku e o cineasta Caimi Waiassé que produzem recursos visuais e materiais que poderiam fazer parte dos recursos didáticos utilizados, tanto nas aldeias, como nas escolas urbanas não indígenas. Além do mais, esse material contribuiria para que os indígenas se sentissem empoderados, como atores do processo educativo.

Em relação às questões envolvendo alunos indígenas, a referida professora diz que tem sido procurada pelos professores, não para falar da cultura, pois a maioria diz saber, mas para aprender como ensinar os alunos indígenas. Porém, a professora faz reflexões importantes:

[...] como lidar se não entendo como ele se relaciona, como se constitui culturalmente [...] eu não dou conta de lidar com ele. Ou quando os professores das escolas da cidade dizem: Ah! Mas ele senta lá no fundo da sala. O professor tem que entender que é uma forma da organização da cultura Xavante. O professor tem que conhecer aspectos culturais; por exemplo, como acontecem as categorias de idade; porque em determinadas idades eu não posso ter menino com menina; se eu tiver um adolescente na sala, em determinado momento, eu não posso tocá-lo, pois ele está passando por um processo de ritual. Então, tudo faz parte do desafio para eu conseguir ensinar o conteúdo. Eu preciso saber quem é esse aluno primeiro, quem é esse sujeito que está na minha sala. (L.M.R.)

A professora enfatiza a importância da formação continuada realizada pelo CEFAPRO em parceria com a Universidade Federal de Mato Grosso - UFMT - e os professores Xavante, com foco na cultura e na linguística indígenas. Essas formações contribuem com os professores para que possam conhecer melhor a cultura para ensinar os alunos indígenas presentes no contexto escolar urbano.

Além disso, a professora pontuou que o estado tem políticas de inclusão, a partir da lei n. 11.645, de 10 março de 2008 e das Orientações Curriculares, mas nenhum projeto efetivo tem sido desenvolvido para atender a demanda das escolas. $\mathrm{O}$ estado tem desencadeado ações pontuais em parceria com algumas instituições como a FUNAI, que realizou, em 2016, a Mostra de Cinema Xavante.

Diante do exposto, faz-se necessária maior efetivação da formação continuada e da produção de material didático, a fim de que os professores conheçam a cultura indígena e desenvolvam ações didático-pedagógicas para incluir as minorias.

Sobre as questões que envolvem a discriminação e os preconceitos, em relação aos alunos indígenas, a maioria dos professores diz que não tem presenciado agressões. Somente uma professora disse que "[...] já ouviu relatos de professor que presenciou casos de discriminação com alunos indígenas. A sociedade é muito preconceituosa e casos de 
discriminações ocorrem todos os dias" (D.D.O. ${ }^{3}$ ). Embora esse tipo de agressão seja silenciado, ele está presente no contexto escolar. Os estudos de Grupioni (1995) mostram que a pouca compreensão da cultura indígena acaba contribuindo com atitudes discriminatórias. Para M.L.A. é necessário fazer frente à incompreensão da sociedade e à falta de compromisso das políticas educacionais que deixam de atender as necessidades das escolas da cidade para incluir os alunos indígenas.

Em relação a isso, os estudos de Grupioni chamam a atenção para o fato de que cada cultura vê o mundo a partir de seus pressupostos e isso pode provocar uma valorização do próprio grupo e desencadear " [...] uma visão distorcida e preconceituosa em relação aos demais" (GRUPIONI, 1995, p. 481). Assim, as crenças se formam a partir de determinados grupos, mas não constituem parte da natureza humana. Para superar isso, precisamos perceber que “[...] somos uma cultura, um grupo, e mesmo uma nação, no meio de muitas outras. Que nossas explicações são particulares, específicas e diferentes das de outros grupos, que também têm as suas" (GRUPIONI, 1995, p. 481).

Tal compreensão nos remete à fala de um entrevistado que diz: “[...] a contemplação da diversidade cultural e a presença dos povos indígenas no currículo escolar, precisa ser compreendida como resultado de uma longa luta dos movimentos indígenas por visibilidade e reconhecimento" (D.D.O ${ }^{4}$.

O preconceito vivenciado pelos alunos indígenas reflete uma educação precária, uma vez que “[...] a imagem construída dos povos indígenas é baseada em estereótipos, ideias falsas, que igualam e colocam sob um mesmo rótulo um sem número de situações diversas" (REZENDE, 2009, p. 54). Essa concepção é resultante do pouco conhecimento a respeito da cultura indígena. Isso faz com que alunos de diferentes etnias avancem pouco no processo de aprendizagem, mais especificamente quando frequentam escolas não indígenas, como tem sido o caso de alunos Xavante que permanecem, por anos, na escola, sem conseguir se apropriar das noções básicas de leitura e escrita do português brasileiro. Assim, essas dificuldades podem estar relacionadas, segundo Giaccaria (Apud REZENDE, 2009), à formação cultural diferente, à língua diferente e à falta de conhecimento da cultura dos indígenas.

Nessa mesma linha de pensamento, o professor C.T.T. diz que os professores da rede Básica de Ensino de Barra do Garças ainda precisam se preparar melhor para trabalhar com os estudantes indígenas, de forma satisfatória. Para ele a questão da língua tem sido uma das

\footnotetext{
3 - Entrevista realizada em agosto de 2017.

4 - Entrevista realizada em agosto de 2017.
} 
barreiras, tanto que "[...] há 10 anos venho batalhando junto a SEDUC de Mato Grosso para que o aluno indígena tenha um acompanhante, intérprete, mas não obtive êxito ainda" (C.T.T ${ }^{5}$.).

Nessa perspectiva, os estudos de Oliveira (2014) mostram que a crítica ao desempenho do aluno indígena revela as fragilidades enfrentadas para apropriar-se da língua portuguesa, sendo este um dos desafios a ser vencido, também, pelos Xavante.

Outra questão trazida pelo professor diz respeito à pouca aceitação da população barragarcense em relação à cultura Xavante, mesmo sabendo que a sociedade passa por transformações. Nesse sentido,

\begin{abstract}
O que as comunidades indígenas esperam da sociedade envolvente não é que lhes (re) ensinem suas tradições, nem que os não-índios determinem os traços culturais a serem preservados, pois esta seleção e adaptação só pode ser realizada plenamente pelo próprio grupo indígena. $\mathrm{O}$ que eles esperam é o respeito às suas diferenças, acesso aos conhecimentos e técnicas 'habitualmente manipuladas pelos brancos' desde que seus direitos e tradições sejam preservados (GOMES et al, 2012, p. 424).
\end{abstract}

Esse desejo ainda está distante de efetivar-se na sociedade e também no contexto das escolas urbanas que atendem alunos indígenas, em busca de formação em outros espaços, diferentes das aldeias, mas que acabam sendo ignorados, discriminados e excluídos do processo de ensino-aprendizagem.

Para avançar no processo de inclusão dos indígenas nas escolas não indígenas faz-se necessário, por um lado, que as políticas públicas sejam mais efetivas nas instituições de ensino e, por outro, investimento teórico, debates e discussões, tanto nos cursos de formação inicial, como na continuada dos profissionais da educação, para um melhor entendimento a respeito das diferenças socioculturais, para mediar didaticamente o processo de ensino-aprendizagem desses cidadãos em suas identidades culturais.

\title{
6 CONSIDERAÇÕES
}

Este estudo teve como objetivo entender o processo de inclusão dos alunos indígenas que frequentam as escolas públicas não indígenas na cidade de Barra do Garças/MT. Isso possibilitou a realização de reflexões sobre a Educação Escolar Indígena, no Brasil, após mais de 500 anos de resistência dos povos indígenas ao processo de colonização e de suas conquistas, a partir da Constituição Federal de 1988, e demais leis que regulamentam os direitos conquistados.

Ao abordar o tema inclusão de alunos indígenas, em sala de aula, buscamos dar visibilidade às dificuldades que envolvem esses alunos no contexto escolar do não indígena.

\footnotetext{
5 - Entrevista realizada em agosto de 2017.
} 
Nesse espaço, percebemos contradições que merecem reflexões, em relação ao que é determinado pelas políticas educacionais com a realidade vivenciada nas escolas de Educação Básica da Rede Estadual de Mato Grosso.

As constantes reivindicações e movimentos indigenistas, em prol de uma educação escolar inclusiva, têm feito com que o Estado Brasileiro garanta o acesso, a permanência e o atendimento diferenciado a esses povos. Isso tem permitido que alunos indígenas se desloquem das aldeias para estudar em escolas não indígenas. Não raras vezes, essa inserção tem desencadeado certo desconforto aos profissionais das escolas que se sentem despreparados para atender à diversidade, dentre elas, a étnica.

Sendo a escola um espaço de ensino-aprendizagem, ela precisa enfrentar os desafios, principalmente em relação à língua e à cultura dos povos indígenas, em especial dos Xavante. Porém, os dados sinalizam para a pouca preparação dos profissionais da educação para atender essa demanda. Isso requer políticas educacionais mais efetivas para incluir os indígenas no contexto escolar não indígena.

Para tanto, faz-se necessário reconhecer a dívida histórica que o Brasil tem com os povos indígenas, mais especificamente no que se refere à inserção dos alunos na educação escolar e conhecer a cultura dos povos indígenas e suas histórias. Isso demanda recursos didáticopedagógicos e investimentos na formação inicial e continuada dos profissionais da educação, a fim de que possam ensinar e aprender com os povos indígenas, tanto no que se refere à língua quanto às tradições culturais.

\section{REFERÊNCIAS}

AZEVEDO, Marta Maria. Povos indígenas no Brasil 2006-2010. In: Instituto

Socioambiental Povos Indígenas no Brasil. Disponível em:

$<$ http://pib.socioambiental.org/pt/c/no-brasil-atual/quantos-sao/o-censo-2010-e-os-povosindigenas>. Acesso em: 23 jan. 2017.

BRASIL. Instituto Brasileiro de Geografia e Estatística (IBGE). Os indígenas no censo demográfico 2010. Povos indígenas no Brasil. Disponível em:

〈http://indigenas.ibge.gov.br/images/indigenas/estudos/indigena_censo2010.pdf > . Acesso em: 15 dez. 2016.

BRASIL. Lei de Diretrizes e Bases da Educação Nacional - LDBN. 9394/96. Disponível em: 〈https://www2.senado.leg.br/bdsf/bitstream/handle/id/70320/65.pdf>. Acesso em: 26 fev. 2017.

BRASIL. Referencial curricular nacional para as escolas indígenas. Ministério da Educação. Brasília: MEC/SEF, 2002. 
BONIN, Iara Tatiana. Encarte pedagógico 1- Culturas indígenas na sala de aula. Publicação Conselho Indigenista Missionário, 2012. 4p. Disponível em:

<http://www.cimi.org.br/pub/EncartePedagogico_JanFev.pdf $>$. Acesso em: 25 mar. 2017.

BOTH, Sérgio José. Da aldeia à cidade: estudantes indígenas em escolas urbanas. v. 9. Cuiabá: EdUFMT, 2009. 154 p. (Coletânea educação escolar indígena).

COHN, Clarice. Culturas em transformação: os índios e a civilização. São Paulo em Perspectiva. v. 15, n.2, p.36-42, 2001. Disponível em:

<http://www.scielo.br/scielo.php?script=sci_serial\&pid=0102-8839\&lng=en\&nrm=iso $>$. Acesso em: 24 jan. 2017.

DELUCI, Luciana Akeme Sawasaki Manzano. Ti’aroptsimani ‘̃̃: Os A’weMarãiwatsédé tecem saberes para a construção de uma proposta curricular intercultural. 2013. 186 p. Dissertação (Mestrado em Desenvolvimento Sustentável). Centro de Desenvolvimento Sustentável, Universidade de Brasília, Brasília, 2013.

FRANCO, Patrik Thames. A Educação Escolar Indígena em Goiás: Um estudo a partir da política indigenista da FUNAI (1967-1991). 2008. 21 p. Trabalho de Conclusão de Curso (Graduação em Antropologia), Universidade Federal de Goiás-UFG, 2008.

GOMES, R. L. AGUIAR, R.B.R. ALEXANDRE, I.V. O desrespeito às diferenças na cultura indígena. Revista Eventos Pedagógicos. v.3, n.2, 422 - 429 p. Maio - Jul. 2012. Disponível em: 〈http://sinop.unemat.br/projetos/revista/index.php/eventos >. Acesso em: 01 abr. 2017.

GRUPIONI, Luís Donisete Benzi. Livros didáticos e fontes de informações sobre as sociedades indígenas no Brasil. In: SILVA, Aracy Lopes da; GRUPIONI, Luís Donizete Benzi. (Orgs.). A temática indígena na escola: novos subsídios para professores de $1^{\circ} \mathrm{e} 2^{\circ}$ graus. Brasília: MEC/MARI/UNESCO, 1995.

INSTITUTO SOCIOAMBIENTAL. Povos Indígenas no Brasil. Disponível em: $<$ https://pib.socioambiental.org/pt/c/0/1/2/populacao-indigena-no-brasil >. Acesso em: 28 jan. 2017.

LAKATOS, Eva Maria; MARCONI, Marina de Andrade. Fundamentos de Metodologia Científica, 5 ed., São Paulo, editora Atlas, 2003.

LÜDKE, Menga; ANDRÉ, Marli Eliza Dalmazo Afonso de. Pesquisa em educação: abordagens qualitativas. São Paulo: EPU, 1986.

LIMA, Marilva Vilela de Sousa. Inclusão escolar de pessoas com deficiência. 2016. 85 p. Trabalho de Conclusão de Curso (Graduação Licenciatura em Geografia) - Instituto de Ciências Humanas e Sociais, Universidade Federal de Mato Grosso-UMT, Barra do Garças, 2016.

MORAES, Alexandre de. (Orgs.). Constituição da República Federativa do Brasil. 41.ed. São Paulo: Atlas, 2015.

MATO GROSSO. Assembleia Legislativa - ALMT Constituição do Estado de Mato Grosso: texto Constitucional promulgado em 5 de outubro de 1989. Cuiabá: ALMT, 1989. 
MATO GROSSO. Secretaria de Estado de Educação. Plano Estadual de Educação.

Secretaria de Estado de Educação de Mato Grosso. Cuiabá, 2014.

MATO GROSSO. Secretaria de Estado de Educação. Orientações Curriculares:

Diversidades Educacionais. Secretaria de Estado de Educação de Mato Grosso. Cuiabá:

Defanti, 2012.

OLIVEIRA, Natália Araújo de. Ser Xavante, morar e estudar na cidade: Os Xavante em Nova Xavantina/MT. Rev. Patrimônio e Memória, São Paulo, UNESP, v. 10, n. 2, p. 235-253, julho-dezembro, 2014. Disponível em:

<http://pem.assis.unesp.br/index.php/pem/issue/view/17/showToc>. Acesso em: 03 fev. 2017.

PAGLIARO, H.; AZEVEDO, M.M.; SANTOS, R.V. Demografia dos povos indígenas no Brasil. Rio de Janeiro: Editora FIOCRUZ, 2005. 192 p. Disponível em:

<http://books.scielo.org>. Acesso em: 26 jan. 2017.

REZENDE, Gerson Carlos. A relação entre indígenas e não-indígenas na zona urbana: fronteira cultural. v. 08. Cuiabá: EdUFMT, 2009. (Coletânea Educação Escolar Indígena).

RIBEIRO, Darci. Culturas e línguas indígenas do Brasil. Educação e Ciências Sociais, Rio de Janeiro, v. 2, n. 6, 1957, 1-102 p.

SOUZA, Ederval Pereira de. Cultura, Memória e Teorias em Educação: O Ensino da História e Cultura dos Povos Indígenas nas Escolas Municipais de Barra do Bugres/MT, 2016. Pontifícia Universidade Católica do Rio Grande do Sul. Disponível em: <http://www.seduc.mt.gov.br/SiteAssets/Paginas/Forms/ARRUMADAS/PROJETO\%20MES TRADO\%20UFMT_ARTIGO.pdf>. Acesso em: 23 jan. 2017.

SIMAS, Hellen Cristina Picanço. Desafios da Educação Escolar Indígena. Revista Escrita. n. 11, Ano 2010. Disponível em: <http://www.dbd.puc-rio.br/sitenovo/\#tour01〉. Acesso em: 28 jan. 2017.

Recebido em: 27 de Março de 2019.

Aprovado em: 22 de Junho de 2019. 